\title{
Expansão Rápida da Maxila e Constrição Alternadas (ERMC-Alt) e técnica de Protração Maxilar Ortopédica Efetiva: extrapolação de conhecimentos prévios para fundamentação biológica
}

\author{
Alberto Consolaro*, Maria Fernanda M-O. Consolaro**
}

Quando dois ou mais ossos se relacionam para promover movimentos em algumas partes do corpo, essas regiões estrutural e fisiologicamente são identificadas genericamente como articulações ou junturas. O termo juntura advém do latim junkturah e significa união entre duas coisas ${ }^{6}$.

Se na relação entre dois ossos houver uma estreita faixa de tecido conjuntivo fibroso denso, sem articular movimentos para a região, este tipo de juntura recebe o nome de sutura. O termo sutura no latim suo significa costura ${ }^{6}$.

Uma articulação sem qualquer movimento recebe a denominação de sinartrose, se o tecido interposto entre os ossos for tecido conjuntivo fibroso denso. No grego sy e arthron significa com e união. Mas, se houver interposição de cartilagem entre os ossos esta articulação passa a ser classificada como sincondrose. No grego syn e chóndros significa com e cartilagem.

As articulações referidas como sindesmoses promovem pequenos movimentos e possuem um pouco mais de tecido conjuntivo fibroso denso interposto. No grego sýndesmos implica em união, ligação ou ligamento. Isto ocorre entre as extremidades distais do rádio e da ulna. Os movimentos semelhantes àqueles do prego em sua cavidade, caracterizam as articulações denominadas de gonfose, tal como na articulação alvéolo dentária. No grego gonphos é igual a cravo, rebite ou cavilha.

Os nomes que cada articulação recebe está relacionado com a composição de suas margens ósseas, com o tecido interposto e com a sua organização no espaço limitados pelas extremidades ósseas. Estes mesmos fatores determinam o seu comportamento biomecânico.

A sutura palatina mediana une as maxilas e ossos palatinos, no plano sagital me-

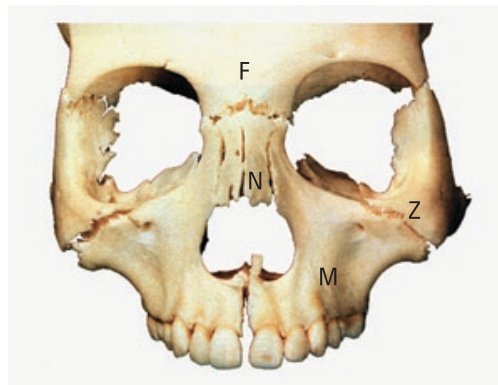

FIGURA 1 - Maxilas (M) e suas relações suturais com outros ossos da face como os zigomáticos (Z), nasais (N) e frontal (F), também envolvidos no Protocolo semanal repetitivo de Expansão Rápida da Maxila e Constrição Alternadas ou "ERMC-Alt" e na técnica de Protração Maxilar Ortopédica Efetiva. diano e desempenha importante papel no crescimento craniomandibular. Por isto sua manipulação pode corrigir ortopedicamente deficiências no desenvolvimento da maxila $a^{7,9,10,11,12,14,15,17,18}$ e, em conseqüência do terço médio da face, em procedimento conhecido como Expansão Rápida da Maxila (ERM). Quando houver a limitação absoluta de movimentação e ou abertura da sutura palatina mediana por formação de pontes ósseas entre as duas maxilas e entre os ossos palatinos pode-se providenciar a Expansão Rápida da Maxila via cirúrgica ou cirurgicamente assistida ${ }^{16}$. Em ambas o uso de aparelhos expansores é necessário.

\footnotetext{
* Prof. Titular de Patologia da FOB-USP e da Pós-Graduação na FOB e FORP-USP.

** Mestre e Doutora pela FOB-USP - Ortodontista Privada em Bauru - SP.
} 
A sutura palatina mediana humana, em vista frontal é sinuosa e imbricada em suas margens ósseas (Fig. 1); o seu tecido conjuntivo fibroso denso de preenchimento apresenta-se organizado em várias camadas celulares (Fig. 2, 3). A morfologia macroscópica e microscópica da sutura palatina mediana ${ }^{13,18,19,20}$. Quanto à sua organização em toda a extensão, incluindo-se as suas modificações comparativamente quanto à idade em ratos, coelhos, macacos e humanos foi detalhadamente estudada por Ennes ${ }^{3}$ em sua tese de doutoramento em 2002.

Para compreender os eventos biológicos envolvidos nos procedimentos terapêuticos ortodônticos, ortopédicos e cirúrgicos no terço médio da face, o conhecimento da organização estrutural da sutura palatina mediana, em toda sua extensão e em diferentes períodos cronológicos, se faz necessário. Além da sutura intermaxilar (Fig. 1), outras suturas circunjacentes do esqueleto fixo da face são envolvidas nos procedimentos de Expansão

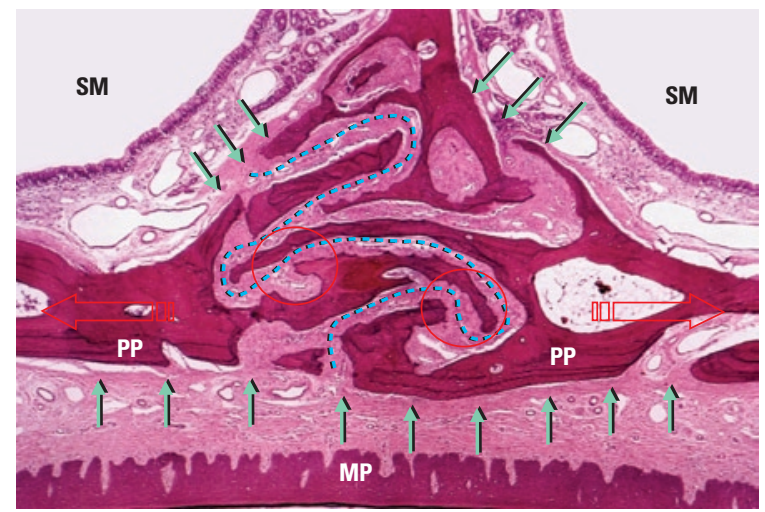

FIGURA 2 - Trajeto sinuoso (linha pontilhada) da sutura palatina mediana de macaco prego adulto jovem (Cebus apella), muito semelhante a dos humanos, a partir da qual podemos prever o local onde haverá os principais eventos teciduais de ruptura, estresse e inflamação na Expansão Rápida da Maxila. 0 tecido conjuntivo fibroso denso desorganizado permitirá o deslocamento lateral das lâminas ósseas (setas grandes e vermelhas). Inevitavelmente pelo trajeto sinuoso alguns locais da superfícies ósseas se tocarão fisicamente (círculos vermelhos). Nestes locais haverá reabsorção óssea e diminuição, ao menos temporária, da sinuosidade sutural. Se esta expansão se alternar repetitivamente com áreas de constrição da sutura, no final de aplicação do protocolo ERMC-Alt o tecido conjuntivo deverá estar menos fibroso e pouco organizado e o trajeto muito menos sinuoso e imbricado. As setas delimitam o periósteo que reveste a superfície óssea externa, inclusive nas áreas das suturas (MP = mucosa palatina; $\mathrm{SM}=$ seio maxilar; $\mathrm{PP}=$ processo palatino da maxila) (fotomicrografia da tese de doutoramento de Ennes ${ }^{3}, 2002$ ).
Rápida da Maxila (ERM) como: sutura pterigopalatina, nasomaxilar, frontomaxilar, zigomaticomaxilar, frontonasal, zigomaticotemporal, zigomaticofrontal, podendo afetar inclusive as suturas fronto-orbitárias, muitas vezes gerando tensão nas estruturas da base do crânio ${ }^{5,7,22,23}$.

Em 2003, Liou e Chen ${ }^{11}$ propuseram, de forma pioneira, um protocolo semanal repetitivo de Expansão Rápida da Maxila e Constrição Alternadas ou "ERMC-Alt" ou Alternate Rapid Maxillary Expansions and Constrictions (Alt-RAMEC), para pacientes com fissura bilateral completa para corrigir deslocamentos assimétricos do segmento anterior da maxila e a posterior protração. Isto promove melhores condições para a realização de enxertos ósseos na área da fissura e corrigindo a retrusão maxilar, característica da face destes pacientes $^{11,12}$.

Em seguida, após o sucesso clínico da Expansão Rápida da Maxila e Constrição Alternadas (ERMC-Alt) em pacientes fissurados e do proto-

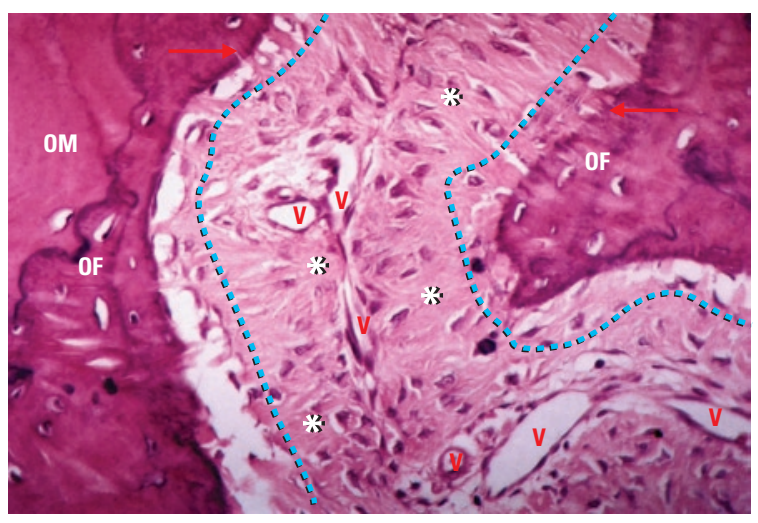

FIGURA 3 - Sutura palatina mediana do macaco prego adulto jovem (Cebus apel/a), muito semelhante à dos humanos. 0 tecido conjuntivo fibroso denso de preenchimento da sutura se relaciona com as margens ósseas a partir de fibras de Sharpey (setas). Os osteoblastos e pré-osteoblastos se posicionam justapostas à superfície como delimita as linhas pontilhadas. Os fibroblastos e células indiferenciadas ocupam a região mais central das suturas e constituem a maior parte do tecido conjuntivo juntamente com a matriz extracelular $\left({ }^{*}\right)$ com grande quantidade de fibras colágenas. Há grande quantidade de vasos sanguíneos (V). Na superfície óssea se destaca a presença de osso fasciculado (OF), semelhante ao ligamento periodontal (OM = osso maduro ou lamelar) (fotomicrografia da tese de doutoramento de Ennes ${ }^{3}, 2002$ ). 
colo preexistente de Expansão Rápida da Maxila e Protração Maxilar para pacientes Classe III em crescimento, Liou extrapolou a utilização do mesmo mecanismo de expansão e contrição também para estes pacientes, propondo a técnica de Protração Maxilar Ortopédica Efetiva.

Para Ngan et al. ${ }^{14,15}$, além de corrigir as discrepâncias transversais maxilares como mordidas cruzadas, muitas vezes presentes nos pacientes Classe III em crescimento, o procedimento de ERM tem como objetivo "desarticular" a maxila e desorganizar as suturas circumaxilares permitindo o deslocamento anterior da maxila por meio de protração com máscara facial.

Ao considerar-se que uma única expansão não seria suficiente para "desarticular" a maxila o suficiente e que uma super-expansão seria indesejada e inconveniente para a oclusão, a proposição do protocolo ERMC-Alt sugere expandir e constritar a maxila por diversas vezes, objetivando desorganizar as suturas de forma mais ampla, permitindo uma protração mais eficiente e exuberante. $\mathrm{O}$ procedimento promove uma distração osteogênica sutural, tanto na sutura intermaxilar no sentido transversal, quanto nas demais, também nos sentidos ântero-posterior e vertical ${ }^{9,10}$.

A técnica de Protração Maxilar Ortopédica Efetiva, portanto, consiste na aplicação do protocolo ERMC-Alt com um parafuso expansor específico e patenteado que promove um deslocamento anterior mais eficiente que os convencionais. A posterior protração maxilar é realizada com uma mola intrabucal também específica e patenteada, que dispensa a colaboração do paciente.

A máscara facial também pode ser utilizada quando o quesito cooperação do paciente não for um problema; porém demanda mais tempo de uso para a obtenção dos mesmos resultados promovidos pela mola intrabucal ${ }^{9,10}$. Enquanto a quantidade de protração maxilar obtida em um único processo de ERM seguida pela utilização de máscara facial é de 1,5 a $3 \mathrm{~mm}$ por ano ${ }^{14}$, a nova técnica de Protração Maxilar Ortopédica Efetiva promove um avanço maxilar médio de $5,8 \mathrm{~mm}^{9,10}$.

O período total de aplicação da técnica de Protração Maxilar Ortopédica Efetiva compreende seis meses, em três estágios a seguir, incluindo o procedimento de ERMC-Alt ${ }^{9}, 10$ :

1) Realização de ERMC-Alt por sete a nove semanas. Uma volta por dia de ativação do parafuso expansor durante sete dias e posterior constrição de uma volta diária por mais sete dias, e assim por diante;

2) Um ou dois meses de protração maxilar, ativando a mola intrabucal;

3) Dois a três meses de contenção, sem ativações adicionais na mola intrabucal de protração maxilar.

A partir do conhecimento adquirido na orientação do trabalho de Ennes ${ }^{3}$ em 2002, as suturas palatinas medianas de primatas e humanos são preenchidas por tecido conjuntivo fibroso denso com suas fibras e células organizadas em fascículos ou feixes que se fundem na superfície óssea como fibras de Sharpey do ligamento periodontal (Fig. $3)$. Entre os feixes de fibroblastos e fibras colágenas observam-se numerosos vasos e, circundandoos, têm-se um tecido conjuntivo frouxo, pobre em fibras e células para que os líquidos e células entrem e saiam dos vasos com maior facilidade; o fluxo é facilitado quanto mais a matriz extracelular for gelatinosa e menos colagênica.

Na superfície óssea da sutura palatina, e provavelmente nas demais suturas da maxila com outros ossos da face, estão justapostos os osteoblastos e pré-osteoblastos em uma camada celular mais ou menos organizada sobre a camada de osteóide, ou osso ainda não mineralizado, ora de aspecto lamelar, ora como osso fasciculado (Fig. 3), tal como ocorre também no ligamento periodontal. A comparação da morfologia microscópica entre a sutura palatina mediana e o ligamento periodontal é quase inevitável ${ }^{4,19}$, muito embora na superfície óssea alveolar o osso fasciculado revista continuadamente e na sutura palatina mediana isto ocorra apenas em algumas partes de suas superfícies 
ósseas. Outra diferença está na presença de cordões e ilhotas de células epiteliais próprias do ligamento periodontal e conhecidas como restos epiteliais de Malassez, ausentes no tecido conjuntivo da sutura palatina mediana.

Muito embora tenha se tentado estratificar as células do tecido conjuntivo da sutura palatina mediana ${ }^{8,21}$ dividindo-as em camadas precisas, delineá-las representa uma tarefa difícil. Podemos afirmar ${ }^{3}$ que entre as duas superfícies ósseas desta sutura (Fig. 3) têm-se:

1) superfícies ósseas formadas ora por osso fasciculado, ora por osso lamelar;

2) recobrimento das superfícies ósseas por osteoblastos e pré-osteoblastos organizados como uma única camada celular;

3) região mais central da sutura constituída por feixes e fascículos de fibroblastos e fibras colágenas que fazem parte da matriz extracelular.

Além de fibras colágenas, a matriz extracelular tem ainda fibras elásticas, proteoglicanas e glicoproteínas, estas duas últimas constituem um verdadeiro gel ligante para os demais componentes, incluindo-se as células conjuntivas e ósseas. Nesta área central sutural outras células podem estar presentes de permeio aos fibroblastos como células ósseas progenitoras, pré-osteoblastos, células indiferenciadas, precursores de clastos, macrófagos e outras eventuais células transeuntes como eventuais leucócitos.

Quando ocorre a Expansão Rápida da Maxila o tecido conjuntivo fibroso denso sutural se desorganiza, o padrão fascicular do conjuntivo se perde, áreas hemorrágicas se misturam ao acúmulo de fibrina e um exsudato inflamatório seroso e o infiltrado neutrofílico se estabelece por 1 a 2 dias. Depois deste período médio o exsudato em sua maior parte é absorvido pelas vênulas e vasos linfáticos enquanto que os neutrófilos são substituídos pelos macrófagos organizadores do reparo pela sua grande capacidade de liberar mediadores, tal como as plaquetas presentes nas áreas hemorrágicas. Após 7 dias provavelmente deve existir uma certa reorganização do tecido conjuntivo sutural, mas ainda não o suficiente para dizermos que voltou à normalidade.

Depois de 7 dias da Expansão Rápida Maxilar, uma nova sessão de reabertura da sutura implica em reinício do processo inflamatório agudo que se caracteriza por exuberante exsudato seroso e rico infiltrado neutrofílico. Os neutrófilos neste processo pouco participam, visto que não encontram bactérias com as quais interagiriam para destruílas, pois esta representa sua especialidade. Após 1 a 2 dias sem exercer sua função, os neutrófilos desaparecem do local e cedem lugar aos macrófagos. Os macrófagos são precursores dos clastos e podem dar origem a estes em alguns locais da sutura para promoverem reorganização da superfície óssea exposta a um processo inflamatório e reparador, remodelando-a, como aconteceria em qualquer outra superfície óssea nestas mesmas condições. Em 2007, esquematicamente, propusemos $^{1}$ a seqüência destes fenômenos em esquemas ilustrativos na Revista Clínica de Ortodontia Dental Press.

Depois de repetido este processo por 6 vezes, como preconiza-se nos Protocolos propostos inicialmente por Liou ${ }^{9,10,11,12}$, o grau de organização celular e fibrosa do tecido conjuntivo fibroso denso sutural e da superfície óssea envolvida é muito pequeno e pouco resistente. As fibras de Sharpey não tem como se estabelecerem firmemente na superfície óssea em constante remodelação, os feixes fibrosos e os fibroblastos perdem seu alinhamento clássico e a matriz extracelular em sua maior parte está em recomposição fibrosa e substituída por exsudato inflamatório seroso constante e periodicamente formado e reformado na área sutura. Nos tecidos conjuntivos fibrosos densos o exsudato e o infiltrado inflamatório se formam e ocupam espaço a partir da dissolução da matriz extracelular, inclusive digerindo enzimaticamente as fibras colágenas.

No final do período preconizado pelos Protocolos propostos a maxila estará praticamente 
quase "solta" nas suas relações suturais com os demais ossos da face e da base do crânio. Em outras palavras a maxila facilmente pode ser expandida lateralmente e protraída para corrigir distorções de posicionamento e crescimento no terço médio da face.

O tecido conjuntivo fibroso denso sutural não se continua naturalmente com o tecido conjuntivo dos tecidos moles que revestem os ossos, inclusive a maxila (Fig. 2). Nas superfície ósseas, inclusive nas áreas de sutura, há o revestimento das mesmas pelo periósteo ${ }^{2}$ que se insere firmemente nas corticais graças à união de fibras colágenas que partem de sua parte mais externa em direção à interface cortical-periósteo. O periósteo tem duas camadas bem definidas: uma mais interna, ricamente celularizada e vascularizada e que constitui a interface cortical periósteo, e uma segunda camada mais externa, extremamente fibrosa e densa, pouco celularizada e delimita os limites externo do osso e que interfaceia com o tecido conjuntivo fibroso não relacionado com à biologia óssea (Fig. 2).

O ambiente das suturas desorganizadas e fragilizadas da maxila com os demais ossos em decor- rência dos Protocolos propostos deve estar compartimentalizado pelo periósteo, ou seja, estará protegido, delimitado e circunscrito. Isto impede que células estranhas ao tecido ósseo colonizem o espaço sutural. Caso isto aconteça poderia ter lugar uma osteoartrose, uma pseudo-articulação por formação de tecido conjuntivo fibroso, praticamente cicatricial, sem origem óssea. O periósteo exerce neste processo um papel importante para que esta manobra terapêutica tenha sucesso biologicamente suportado. Com o tempo, as suturas submetidas a este procedimento se reorganizam em algumas semanas e tenderiam ${ }^{1}$ a voltar à normalidade morfológica e fisiológica.

\section{Consideração Final}

Esperamos, com estas explicações baseadas em extrapolações de conhecimentos prévios, ter contribuído singelamente com a compreensão biológica da aplicação clínica do Protocolo da Expansão Rápida da Maxila e Constrição Alternadas (ERMC-Alt) e da técnica de Protração Maxilar Ortopédica Efetiva que abrem novas perspectivas nas correções ortopédicas e ortodônticas das alterações de crescimento do terço médio da face. 


\section{REFERÊNCIAS}

1. CONSOlARO, A.; CONSOLARO, M. F. M-O. Protocolo semanal repetitivo de expansão rápida da maxila e constrição alternadas e técnica da protração maxilar ortopédica efetiva: Porque? Como? Rev. Clín. Ortodon. Dental Press, Maringá, v. 6, n. 6, p. 110-111, dez./jan. 2007/2008.

2. CONSOLARO, A. et al. O periósteo e a ortopedia dos maxilares. Rev. Dental Press Ortodon. Ortop. Facial, Maringá, v. 6, n. 4, p. 77-89, jul./ago. 2001.

3. ENNES, J. P. Análise morfológica da sutura palatina mediana em ratos, coelhos, macacos e homens em diferentes fases do desenvolvimento cronológico. 2002. 154 f.. 2002. Tese (Doutorado)-Faculdade de Odontologia de Bauru, Universidade de São Paulo, Buaru, 2002.

4. FOLLIN, M. E. et al. A histologic comparative study of midpalatal suture and periodontal ligament tissue in the beagle dog. Scand. J. Dent. Res., Copenhagen, v. 95, no. 1, p. 55-58, Feb. 1987.

5. GARDNER, G. E.; KRONMAN, J. K. Cranioskeletal displacements caused by rapid palatal expansion in the rhesus monkey. Am. J. Orthod., St. Louis, v. 59, no. 2, p. 146-155, Feb. 1971.

6. GOSS, C. M. Junturas e ligamentos. In:___ Gray anatomia. 29th ed. Rio de Janeiro: Guanabara Koogan, 1988. p. 238-240.

7. HOLBERG, C.; STEINHÄUSER, S.; RUDZKI-JANSON, I. Rapid maxillary expansion in adults: cranial stress reduction depending on the extent of surgery. Eur. J. Orthod., Oxford, v. 29, no. 1, p. 31-36, Feb. 2007.

8. KOKICH, V. G. Sutural response to orthopedic forces. In: CARSON, D. S.; GOLDSTEIN, S. A. Bone biodynamics in Orthodontic and orthopedic treatment. Ann Arbor: Ann Arbor Center for Human Growth and Development, 1992. p. $173-188$.

9. LIOU, E. J. Toothborne orthopedic maxillary protraction in Class III patients. J. Clin. Orthod., Boulder, v. 39, no. 2, 68-75, Feb. 2005.

10. LIOU, E. J. W. Effective maxillary orthopedic protraction for growing Class III patients: a clinical application simulates distraction osteogenesis. Prog. Orthod., Berlin, v. 6, no. 2, p. 154-171, 2005.
11. LIOU, E. J. W.; CHEN, P. K. T. New orthodontic and orthopaedic managements on the premaxillary deformities in patients with bilateral cleft before alveolar bone grafting. Ann. R. Coll. Surg. Engl., London, v. 7, p. 73-82, 2003.

12. LIOU, E. J.; TSAI, W. C. A new protocol for maxillary protraction in cleft patients: repetitive weekly protocol of alternate rapid maxillary expansions and constrictions. Cleft Palate Craniofac. J., Pittsburgh, v. 42, no. 2, p. 21-27, Mar. 2005.

13. MELSEN, B. Palatal growth studied on human autopsy material: a histologic microradiograph study. Am. J. Orthod., St. Louis, v. 68 , no. 1 , p. $42-58,1975$.

14. NGAN, P. et al. Cephalometric and occlusal changes following maxillary expansion and protraction. Eur. J. Orthod., Oxford, v. 20, no. 3, 237-254, June 1998.

15. NGAN P. Early treatment of Class III malocclusion: is it worth the burden? Am. J. Orthod. Dentofacial Orthop., St. Louis, v. 129, p. S82, Apr. 2006. 4 Supplement.

16. NORTHWAY, W.; MEADE, J. B. Surgically assisted rapid maxillary expansion: a comparison of technique response, and stability. Angle Orthod., Appleton, v. 67, no. 4, 1997.

17. PERSSON, M. The role of sutures in normal and abnormal craniofacial growth. Acta Odontol. Scand., Oslo, v. 53, p. 152-161, 1995.

18. PERSSON, M.; THILANDER, B. Palatal suture closure in man from 15 to 35 years of age. Am. J. Orthod., St. Louis, v. 72, no. 1, p. 42-52, July 1977.

19. PIRELLI, P. et al. A comparative light microscopic study of human midpalatal suture and periodontal ligament. Minerva Stomatol., Torino, v. 46, no. 9, p. 429-33, Sept. 1997.

20. PIRELLI, P. et al. A light microscopic investigation of the human midpalatal suture. Ital. J. Anat. Embryol., Firenze, v. 104, no.1, p.11-18, Mar. 1999.

21. PRITCHARD, J. J. et al. The structure and development of cranial and facial sutures. Am. J. Anat., New York, v. 90, p. 73-89, 1956.

22. REMMELINK, H. J. Orientation of maxillary sutural surfaces. Eur. J. Orthod., Oxford, v. 10, p. 223-226, Aug. 1988.

23. WAGEMANS, P. A. H. M. et al. Sutures and forces: a review. Am. J. Orthod. Dentofacial Orthop., St. Louis, v. 94, no. 2, 129-141, Aug.1988.
Endereço para correspondência

Alberto Consolaro

E-mail: alberto@fob.usp.br 